\title{
Differential Roles of Orexin Receptor-1 and -2 in the Regulation of Non-REM and REM Sleep
}

\author{
Michihiro Mieda, ${ }^{1,2,4}$ Emi Hasegawa, ${ }^{1}$ Yaz Y. Kisanuki, ${ }^{2,4,5}$ Christopher M. Sinton, ${ }^{3}$ Masashi Yanagisawa, ${ }^{2,4}$ \\ and Takeshi Sakurai ${ }^{1}$ \\ ${ }^{1}$ Department of Molecular Neuroscience and Integrative Physiology, Faculty of Medicine, Kanazawa University, Kanazawa, Ishikawa 920-8640, Japan, \\ Departments of ${ }^{2}$ Molecular Genetics and ${ }^{3}$ Pathology, ${ }^{4}$ Howard Hughes Medical Institute, University of Texas Southwestern Medical Center, Dallas, Texas \\ 75390-9050, and ${ }^{5}$ Department of Neurology, The Ohio State University Medical Center, Columbus, Ohio 43210
}

Orexin-A and orexin-B are hypothalamic neuropeptides that play critical roles in the maintenance of wakefulness. Intracerebroventricular (ICV) administration of orexin-A has been shown to promote wakefulness and suppress both rapid eye movement (REM) sleep and non-REM (NREM) sleep through the orexin receptor-1 $\left(O X_{1} R\right)$ and orexin receptor- $2\left(O X_{2} R\right)$. Here, we elucidated the differential roles of orexin receptors in the regulation of sleep and wakefulness by comparing the effects of ICV orexin-A administration in wild-type, $O X_{1} R^{-/-}$, and $O X_{2} R^{-/-}$mice. The effects of orexin-A on wakefulness and NREM sleep were significantly attenuated in both knock-out mice as compared with wild-type mice, with substantially larger attenuation in $O X_{2} R^{-/-}$mice than in $O X_{1} R^{-/-}$mice. These results suggest that although the $\mathrm{OX}_{2} \mathrm{R}$-mediated pathway has a pivotal role in the promotion of wakefulness, $O \mathrm{X}_{1} \mathrm{R}$ also plays additional roles in promoting arousal. In contrast, suppression of REM sleep by orexin-A administration was slightly and similarly attenuated in both $O X_{1} R^{-/-}$and $O X_{2} R^{-/-}$mice, suggesting a comparable contribution of the two receptors to REM sleep suppression. Histological studies demonstrated differential distributions of each receptor subtype in distinct neuronal populations with specific neurotransmitter identities in brainstem cholinergic/monoaminergic neurons. In the laterodorsal tegmental and pedunculopontine tegmental nuclei especially, cholinergic neurons exclusively expressed $O X_{1} R$ mRNA, but $O X_{2} R$ mRNA was expressed mainly in GABAergic putative interneurons. Thus, each orexin receptor subtype plays differential roles in gating NREM and REM sleep through distinct neuronal pathways.

\section{Introduction}

Neurons expressing orexins (hypocretins) are distributed within the perifornical lateral hypothalamus and send projections throughout the brain and spinal cord, with particularly dense innervations to nuclei containing monoaminergic and cholinergic neurons constituting the ascending activating system in the brainstem (de Lecea et al., 1998; Sakurai et al., 1998; Peyron et al., 1998; Chemelli et al., 1999; Date et al., 1999; Nambu et al., 1999; van den Pol, 1999). Two subtypes of orexin receptors were also found to be abundantly expressed in these monoaminergic/cholinergic nuclei with distinct distributions (Trivedi et al., 1998;

Received Dec. 13, 2010; revised Feb. 25, 2011; accepted March 9, 2011.

Author contributions:M.M., M.Y., and T.S. designed research;M.M. and E.H. performed research; Y.Y.K. and M.Y. contributed unpublished reagents/analytic tools; M.M. and C.M.S. analyzed data; M.M., C.M.S., and T.S. wrote the paper.

This study was supported in part by the Career Development Award from the Human Frontier Science Program, grants-in-aid for scientific research from the Ministry of Education, Culture, Sports, Science, and Technology (MEXT) of Japan, and the Cabinet Office, Government of Japan through its "Funding Program for Next Generation WorldLeading Researchers." M.Y. is an investigator at the Howard Hughes Medical Institute. We thank S. A. Dixon and S. Sawada for technical assistance, S. Takamori for VMAT2 and VAChT CDNAs, Y. Yanagawa for Gad1 CDNA, and Glaxo SmithKline Pharmaceuticals for synthetic orexin-A.

Correspondence should be addressed to either of the following: Dr. Michihiro Mieda, Department of Molecular Neuroscience and Integrative Physiology, Faculty of Medicine, Kanazawa University, Kanazawa, Ishikawa 920-8640, Japan; E-mail: mieda@med.kanazawa-u.ac.jp; or Dr. Takeshi Sakurai, Department of Molecular Neuroscience and Integrative Physiology, Faculty of Medicine, Kanazawa University, Kanazawa, Ishikawa 920-8640, Japan; E-mail: tsakura@med.kanazawa-u.ac.jp.

DOI:10.1523/JNEUROSCI.6506-10.2011

Copyright $\odot 2011$ the authors $\quad 0270-6474 / 11 / 316518-09 \$ 15.00 / 0$
Marcus et al., 2001). ICV injection of orexin in mice and rats has been shown to increase wakefulness potently and suppress both non-REM (NREM) and REM sleep (Hagan et al., 1999; Piper et al., 2000), at least partly by acting on these monoaminergic/cholinergic neurons. Loss of orexin neurons is associated with narcolepsy in the human, a condition characterized by excessive daytime sleepiness, sleep-onset REM periods, and cataplexy (sudden bilateral skeletal muscle weakness without impairment of consciousness) (Nishino et al., 2000; Peyron et al., 2000; Thannickal et al., 2000), highlighting a critical role of orexins in the maintenance of wakefulness.

Mice with targeted deletion of the prepro-orexin gene (orexin $^{-/-}$ mice) display a phenotype strikingly similar to narcolepsy: brief, abrupt behavioral arrests with muscle atonia (i.e., potentially cataplexy), fragmented wakefulness, and direct transitions from wakefulness to REM sleep (Chemelli et al., 1999). In addition, functionally null mutations in the $\mathrm{OX}_{2} \mathrm{R}$ gene were found in familial narcoleptic dogs (Lin et al., 1999). Consistently, $\mathrm{OX}_{2} \mathrm{R}^{-/-}$mice are also narcoleptic, although their phenotype is significantly milder than that of orexin $^{-1-}$ mice (Willie et al., 2003). In contrast, $O X_{1} R^{-1-}$ mice do not exhibit any overt behavioral abnormalities (Sakurai, 2007; Hondo et al., 2010). These observations suggest that the $\mathrm{OX}_{2} \mathrm{R}$-mediated pathway has a pivotal role, although $\mathrm{OX}_{1} \mathrm{R}$ has an additional role in the regulation of sleep/wake states.

The discovery of a causal link between loss of orexin signaling and narcolepsy has brought about the possibility of novel thera- 
pies for the disorder. Indeed, we previously demonstrated that acute ICV administration of orexin-A maintained wakefulness, suppressed sleep, and inhibited cataplectic attacks in a murine model of narcolepsy (Mieda et al., 2004). Thus, orexin receptor agonists would be of potential value for treating narcolepsy, as well as other conditions of excessive daytime sleepiness in humans. Likewise, dual orexin receptor antagonists, which antagonize both receptors with similar affinity, have been shown to have potential as new medications for the treatment of insomnia (Brisbare-Roch et al., 2007), although single selective $\mathrm{OX}_{2} \mathrm{R}$ antagonists have been reported to be more effective for sleep promotion than dual antagonists in rats (Dugovic et al., 2009). Therefore, analysis of the physiological roles of each receptor in sleep/wakefulness regulation is particularly important to understand the mechanisms of the action of these drugs targeted to orexin receptors.

In the present study, we compared the effects of ICV orexin-A administration on sleep/wakefulness states in wild-type mice, $O X_{1} R^{-/-}$mice, and $\mathrm{OX}_{2} R^{-/-}$mice. In addition, we histologically determined the subtypes of orexin receptors expressed in neurons implicated in sleep/wakefulness regulation.

\section{Materials and Methods}

Animals. Fourteen to 20 week-old male mice from four genotypes (wildtype, $\mathrm{OX}_{1} R^{-/-}, \mathrm{OX}_{2} \mathrm{R}^{-/-}$, and $\mathrm{OX}_{1} \mathrm{R}^{-/-} ; \mathrm{OX}_{2} \mathrm{R}^{-/-}$mice, N5-N6 backcross to $\mathrm{C} 57 \mathrm{BL} / 6 \mathrm{~J}$, generated by crosses between homozygous mice) were used (Willie et al., 2003; Sakurai, 2007). All experimental procedures involving animals were approved by the appropriate institutional animal care and use committees of the University of Texas Southwestern Medical Center at Dallas or Kanazawa University. All efforts were made to minimize animal suffering and discomfort and to reduce the number of animals used.

EEG/EMG recordings following intracerebroventricular administration of orexin- $A$. Mice were anesthetized and implanted with an EEG/EMG implant and a guide cannula as described previously (Mieda et al., 2004). All animals were allowed to recover for at least $10 \mathrm{~d}$ before experiments; mice used for further study had regained their preoperative body weight and exhibited no obvious sign of infection. Before the sleep/wakefulness evaluation, mice were habituated to the experimental procedure by gentle restraint once a day for $2 \mathrm{~d}$ before the experiment.

Each mouse was administered various doses of synthetic orexin-A $(0.3,1$, and $3 \mathrm{nmol}$ in $1 \mu \mathrm{l}$ of sterile artificial CSF per mouse ICV, Glaxo SmithKline Pharmaceuticals) or vehicle at $3 \mathrm{~h}$ into the light phase [zeitgeber time (ZT) 3] using a randomized crossover design at an interval of 3-4 d (Mieda et al., 2004). Mice were then returned to their home cages for immediate recording of EEG/EMG for the subsequent $8 \mathrm{~h}$. Mice were treated with penicillin- $G$ benzathine/penicillin- $G$ procaine suspension $(100,000 \mathrm{U} / \mathrm{kg}$, s.c. $)$ after the surgery and each recording session.

EEG/EMG records were visually scored according to standard criteria of rodent sleep and further analyzed using custom software (Chemelli et al., 1999; Willie et al., 2003). Latencies to NREM sleep and REM sleep were defined as the intervals between the ICV administration and the initiation of the first episodes of NREM sleep and REM sleep, respectively, which continued for at least one epoch (i.e., 20 s).

In situ hybridization. Preparation of coronal brain sections and single in situ hybridization were performed according to procedures previously described (Mieda et al., 2006). For double in situ hybridization, each combination of two antisense riboprobes labeled with either fluoresceinUTP (for VMAT2, VAChT, or Gad1) or digoxygenin-UTP (for $O X_{1} R$ or $\mathrm{OX}_{2} \mathrm{R}$ ) was hybridized to sections simultaneously. Following the chromogen reaction of the first color (blue) obtained with anti-digoxygeninalkaline phosphatase (AP) Fab fragments, 5-bromo-4-chloro-3-indolyl phosphate (Roche) and nitroblue tetrazolium (Roche), sections were rinsed three times with TBS, treated twice with $0.1 \mathrm{~m}$ glycine, $\mathrm{pH} 2.2$, $0.1 \%$ Tween 20 for $5 \mathrm{~min}$, washed, and then incubated with antifluorescein-alkaline phosphatase (AP) Fab fragments. For the chromogen reaction of the second color (orange), 5-bromo-4-chloro-3-indolyl
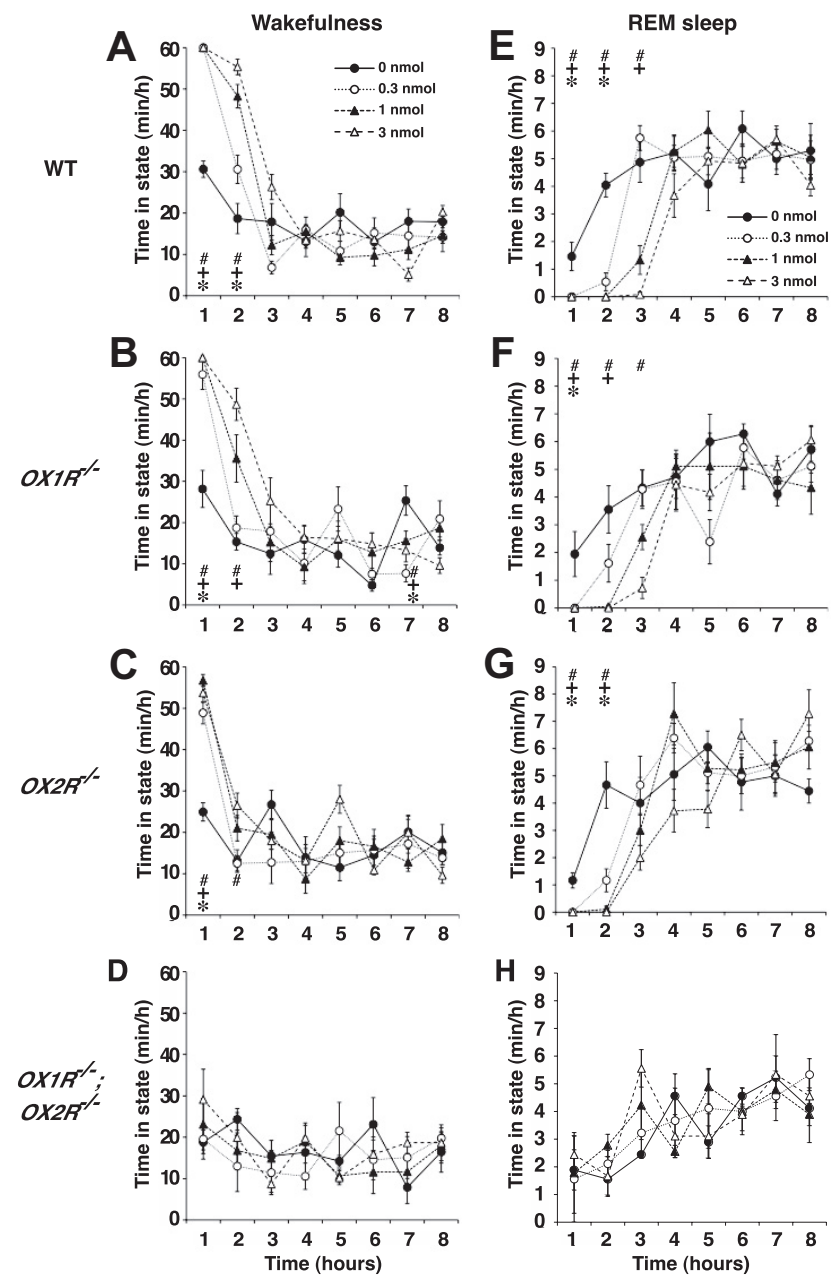

Figure 1. Attenuated effects of ICV orexin-A administration on sleep/wakefulness states in orexin receptor-deficient mice. $\boldsymbol{A}-\boldsymbol{H}$, Hourly plots of time spent awake $(\boldsymbol{A}-\boldsymbol{D})$ and in REM sleep $(\boldsymbol{E}-\boldsymbol{H})$ after ICV orexin-A administration in wild-type (WT) $(\boldsymbol{A}, \boldsymbol{E}), O \mathrm{X}_{1} R^{-/-}(\boldsymbol{B}, \boldsymbol{F}), O \mathrm{X}_{2} R^{-1-}$ $(\boldsymbol{C}, \boldsymbol{G})$, and $O X_{1} R^{-/-} ; O X_{2} R^{-/-}$mice $(\boldsymbol{D}, \boldsymbol{H})$. Since hourly distributions of NREM sleep were essentially mirrored by those of wakefulness in all genotypes examined, those for NREM sleep are not shown. ${ }^{*} p<0.05$ for $0 \mathrm{nmol}$ versus $0.3 \mathrm{nmol}$; ${ }^{+} p<0.05$ for $0 \mathrm{nmol}$ versus $1 \mathrm{nmol}$; ${ }^{\#} p<0.05$ for $0 \mathrm{nmol}$ versus $3 \mathrm{nmol}$; one-way repeated-measures ANOVA and Tukey post hoc tests. Values are mean $\pm \mathrm{SE}\left(n=8\right.$ for wild-type mice, $n=6$ for $O X_{1} R^{-/-}$and $O X_{2} R^{-1-}$ mice, $n=3$ for $O X_{1} R^{-1-} ; O X_{2} R^{-1-}$ mice).

phosphate (Roche) and 2-[4-iodophenyl]-3-[4-nitrophenyl]-5-phenyltetrazolium chloride (Roche) were used.

Antisense riboprobes were synthesized from plasmids containing rat $O X_{1} R$ (NM_013064, nucleotides 824-1813), rat $O X_{2} R$ (NM_013074, nucleotides 23-1439), rat VMAT2 (NM_013031, nucleotides 28-762), rat VAChT (NM_031663, nucleotides 65-2587), and mouse Gad1 (NM_008077, nucleotides 281-821) cDNAs.

Statistical analysis. For the hourly distribution of vigilance states (see Fig. 1), data collected from each strain of mice were analyzed by one-way repeated-measures ANOVA and Tukey post hoc tests to detect significant dose effects. For dose responses of the time spent in each vigilance state and latencies to NREM and REM sleep (see Fig. 2), data of every combination of two mouse strains were analyzed by two-way repeatedmeasures ANOVA to detect significant effects of dose and genotype, followed by post hoc tests to detect significant effects of genotype within each dose. For cumulative time in NREM sleep and REM sleep in $\mathrm{OX}_{2} R^{-/-}$mice (see Fig. $3 A, B$ ), data of every combination of two doses were analyzed by two-way repeated-measures ANOVA to detect significant effects of dose. For percentage of time spent in NREM or REM sleep within $4 \mathrm{~h}$ following 1 or $3 \mathrm{nmol}$ orexin-A administration relative to vehicle administration in $\mathrm{OX}_{2} R^{-/-}$mice (see Fig. $3 C$ ), data were ana- 
lyzed by two-way repeated-measures ANOVA to detect significant effects of dose and vigilance states. For testing correlation between latencies to NREM sleep and REM sleep, Pearson's correlation coefficients were calculated for $O X_{1} R^{-/-}$and $\mathrm{OX}_{2} R^{-1-}$ mice with data of 1 and $3 \mathrm{nmol}$ orexin-A administration. Probability $(p)$ values $<0.05$ were considered statistically significant. Only relevant information from the statistical analysis has been indicated in the text and figures.

\section{Results}

\section{Promotion of wakefulness and suppression of NREM sleep by ICV orexin-A administration}

To further elucidate the differential roles of orexin receptors in sleep/wakefulness regulation, we compared the wakefulnesspromoting and sleep-suppressing effects of ICV orexin-A administration in wildtype, $\mathrm{OX}_{1} \mathrm{R}^{-/-}, \mathrm{OX}_{2} \mathrm{R}^{-/-}$, and $\mathrm{OX}_{1} \mathrm{R}^{-/-}$; $\mathrm{OX}_{2} R^{-/-}$mice. Synthetic orexin-A (0.3, 1 , and $3 \mathrm{nmol} / \mathrm{mouse}$ ) or vehicle was administered into the lateral ventricle at $3 \mathrm{~h}$ into the light phase (ZT3), and EEG/EMG signals were recorded for the subsequent $8 \mathrm{~h}$. The doses and route of administration chosen were comparable to those used previously to examine the effects of orexin-A on behavior and metabolism in rodents (Lubkin and Stricker-Krongrad, 1998; Hagan et al., 1999; Piper et al., 2000;

Stricker-Krongrad et al., 2002). The specific action of orexin-A administration on orexin receptors was further confirmed by the lack of any effect when the neuropeptide was administered to $O X_{1} R^{-/-} ; \mathrm{OX}_{2} R^{-/-}$mice (Figs. $1 D, H, 2$ ).

As previously reported, orexin-A administration in wildtype mice increased wakefulness time in a dose-dependent manner $(n=8, p<0.0001)$ accompanied by a decrease in NREM sleep time $(n=8, p<0.0001)$ (Figs. $1 A, 2 A, B, D)$. These effects continued for $2 \mathrm{~h}$ after administration at all doses examined (Fig. $1 A$ ).

In $O X_{1} R^{-l-}$ mice, the effects of orexin-A administration on wakefulness and NREM sleep were slightly but significantly smaller than those in wild-type mice. The effect of the lowest dose of orexin-A ( $0.3 \mathrm{nmol})$ lasted for only $1 \mathrm{~h}$ in $O X_{1} R^{-1-}$ mice (Fig. $1 B)$. During the first $2 \mathrm{~h}$ after administration, orexin-A increased wakefulness time $(n=6, p<0.0001)$ and suppressed NREM sleep time $(n=6, p<0.0001)$ in a dose-dependent manner in $O X_{1} R^{-/-}$mice, but to a degree significantly less than that in wild-type mice $\left(n=8\right.$ and 6 for wild-type and $O X_{1} R^{-/-}$mice, respectively; $p=0.0078$ and 0.0082 for wakefulness and NREM sleep, respectively) (Fig. $2 A, B$ ). However, the latency to the first episode of NREM sleep after administration in $O X_{1} R^{-1-}$ mice was not significantly different from that in wild-type mice $(n=8$ and 6 for wild-type and $O X_{1} R^{-1-}$ mice, respectively, $p=0.1229$ ) (Fig. 2D).

In contrast, the effects of orexin-A administration in $\mathrm{OX}_{2} \mathrm{R}^{-/-}$ mice were considerably attenuated as compared with those in both wild-type and $O X_{1} R^{-1-}$ mice. Although all doses of orexin-A examined increased wakefulness in $\mathrm{OX}_{2} R^{-/-}$mice in the first hour following administration $(n=6, p=0.0002$ for all
B
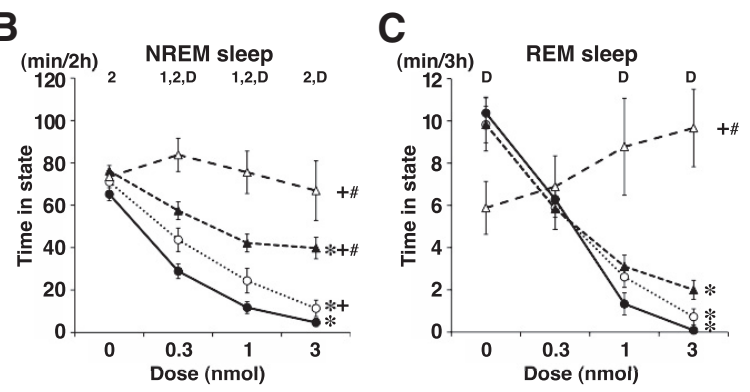

D

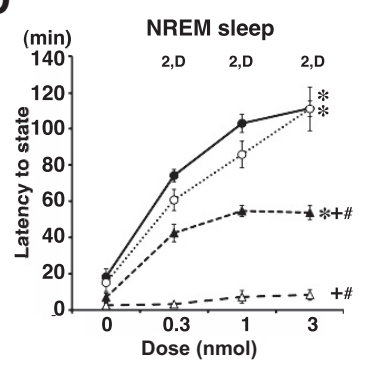

E

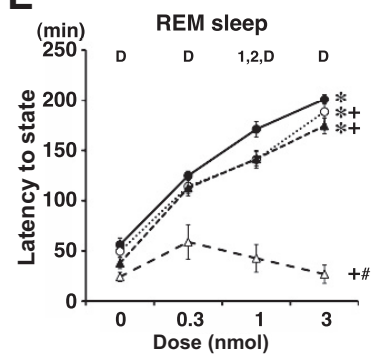

Figure 2. Differential effects on sleep/wakefulness states following activation of $0 X_{1} R$ and $O X_{2} R . A-C$, Dose responses of the effect of ICV orexin-A on time spent awake $(\boldsymbol{A})$, in NREM sleep $(\boldsymbol{B})$, and in REM sleep $(\boldsymbol{C})$ within $2 \mathrm{~h}(\boldsymbol{A}, \boldsymbol{B})$ or $3 \mathrm{~h}(\boldsymbol{C})$ following . Analysis of REM sleep over $3 \mathrm{~h}$ is shown here $(C)$ since the effects on REM sleep persisted longer than those on responses of the effect of ICV orexin-A on latency to the first episode of NREM sleep $(\boldsymbol{D})$ and REM sleep $(\boldsymbol{E})$ following administration. $p 0.05$ for effect of dose in each genotype $(*)$, effect of genotype as compared with wild-type mice $(+)$, and interaction OX $R^{-/-}$(2), and WT versus $O X_{1} R^{-/-} ; O X_{2} R^{-/-}$mice (D) at each dose, by two-way repeated-measures ANOVA. Values are

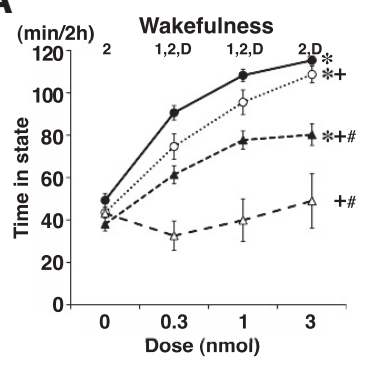
$O R^{-/-} ; O \times 2 R^{-/-}$ 
B LC
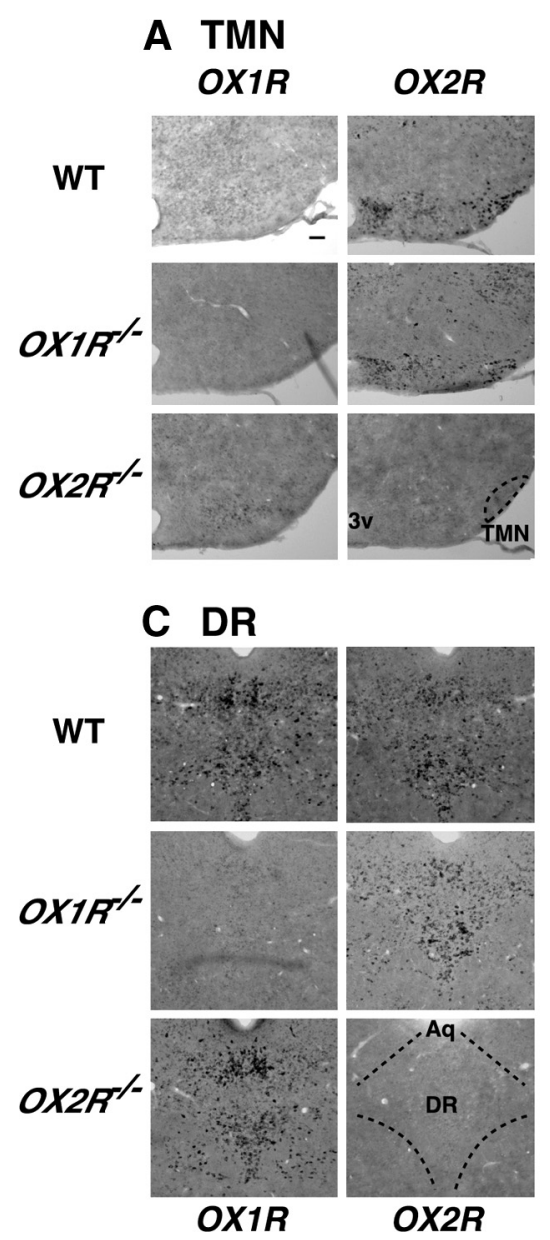

\section{OX1R}

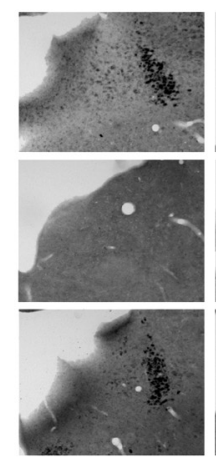

D LDT

OX2R
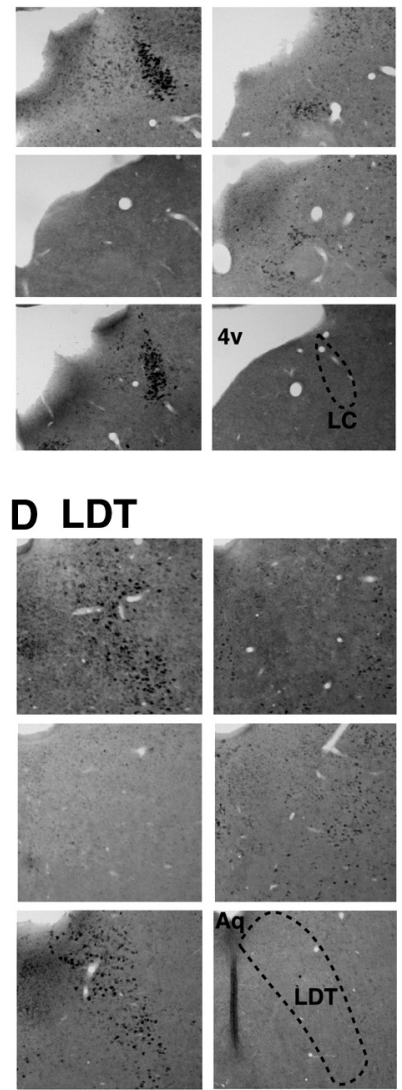

OX1R
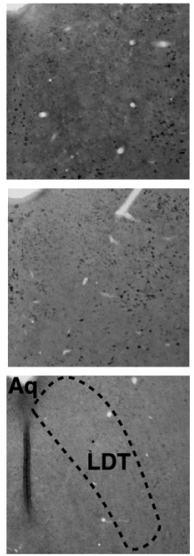

OX2R

Figure 4. Similar distributions of $O X_{1} R$ and $O X_{2} R$ mRNA in wake-active nuclei of wild-type, $O X_{1} R^{-/-}$, and $O X_{2} R^{-/-}$mice. $A-D$, Coronal brain sections containing TMN $(\boldsymbol{A}), \mathrm{LC}(\boldsymbol{B}), \mathrm{DR}(\boldsymbol{C})$, and LDT $(\boldsymbol{D})$ from wild-type, $O X_{7} R^{-/-}$, and $O X_{2} R^{-1-}$ mice were hybridized in situ to an $O X_{1} R$ or $O X_{2} R$ antisense probe. $3 v$, Third ventricle; $4 v$, fourth ventricle; Aq, aqueduct. Scale bar, $100 \mu \mathrm{m}$.

three doses as compared with vehicle), these effects dissipated more rapidly when compared with wild-type and $O X_{1} R^{-1-}$ mice (Fig. 1C). Accordingly, the dose-response curve of $2 \mathrm{~h}$ wakefulness in $\mathrm{OX}_{2} \mathrm{R}^{-/-}$mice was below those of both wild-type ( $n=8$ and 6 for wild-type and $O X_{2} R^{-/-}$mice, respectively, $p=0.0001$ ) and $O X_{1} R^{-1-}$ mice $(n=6, p=0.0012)$, and the dose-response curve of $2 \mathrm{~h}$ NREM sleep in $\mathrm{OX}_{2} \mathrm{R}^{-/-}$mice was above those of both wild-type ( $n=8$ and 6 for wild-type and $\mathrm{OX}_{2} R^{-/-}$mice, respectively, $p<0.0001)$ and $O X_{1} R^{-/-}$mice $(n=6, p=0.0011)$ (Fig. 2A,B). In addition, the latency to NREM sleep after orexin-A administration was significantly shorter than that in wild-type ( $n=8$ and 6 for wild-type and $O X_{2} R^{-/-}$mice, respectively, $p<0.0001)$ and $O X_{1} R^{-1-}$ mice $(n=6, p=0.0003)$ (Fig. $2 D)$. Importantly, although the effect was smaller than observed in the other genotypes, the fact that orexin-A administration increased wakefulness in $O X_{2} R^{-/-}$mice implies that activation of $\mathrm{OX}_{1} \mathrm{R}$ has wakefulness-promoting effects.

Thus, activation of either of the two orexin receptors was sufficient to increase wakefulness, but to a degree significantly less than that with simultaneous activation of both receptors, suggesting that both $\mathrm{OX}_{1} \mathrm{R}$ and $\mathrm{OX}_{2} \mathrm{R}$ mediate the wakefulness-promoting and NREM sleep-suppressing effects of ICV orexin-A administration. We also noted that the contributions of $\mathrm{OX}_{2} \mathrm{R}$ to these effects were substantially greater than those of $\mathrm{OX}_{1} \mathrm{R}$.
Both OX1R and OX2R are similarly involved in orexin-A-mediated REM sleep regulation

As previously reported, orexin-A administration in wild-type mice potently suppressed REM sleep in a dosedependent manner $(n=8, p<0.0001)$ (Figs. $1 E, 2 C, E$ ). REM sleep suppression lasted for $3 \mathrm{~h}(3 \mathrm{nmol}$ and $1 \mathrm{nmol}$ orexin-A) or for $2 \mathrm{~h}(0.3 \mathrm{nmol}$ orexin-A) after administration in wild-type mice (Fig. $1 E$ ).

In both $O X_{1} R^{-/-}$and $O X_{2} R^{-/-}$mice, the effects of orexin-A on REM sleep suppression dissipated more rapidly than in wild-type mice. In $O X_{1} R^{-1-}$ mice, the lower doses of orexin-A $(0.3$ and $1 \mathrm{nmol})$ suppressed REM sleep for 1 and $2 \mathrm{~h}$ after administration, respectively (Fig. $1 F$ ). In $\mathrm{OX}_{2} R^{-/-}$mice, REM sleep suppression lasted for only $2 \mathrm{~h}$ at all doses examined (Fig. 1G). Although the amount of REM sleep in the first $3 \mathrm{~h}$ after administration was not significantly different among the three different genotypes ( $p=0.2835$ for wild-type vs $O X_{1} R^{-l-}$ mice, $p=0.6582$ for wild-type vs $\mathrm{OX}_{2} \mathrm{R}^{-/-}$mice, $p=$ 0.5677 for $O X_{1} R^{-1-}$ vs $O X_{2} R^{-1-}$ mice) (Fig. 2C), the latency to REM sleep after administration was slightly shorter in $O X_{1} R^{-1-}(n=6, p=0.0308)$ and $\mathrm{OX}_{2} R^{-/-}$mice $(n=6, p=0.0004)$ than in wild-type mice $(n=8)$ (Fig. $2 E)$. The latency to REM sleep was not different between $O X_{1} R^{-/-}$and $O X_{2} R^{-/-}$mice $(p=$ $0.3270)$. Thus, REM sleep suppression following orexin-A administration was slightly and similarly attenuated in $O X_{1} R^{-/-}$and $O X_{2} R^{-1-}$ mice when compared with wild-type mice. These results suggest that both $\mathrm{OX}_{1} \mathrm{R}$ and $\mathrm{OX}_{2} \mathrm{R}$ mediate REM sleep suppression with similar efficacy through different and redundant pathways.

Since REM sleep episodes are only observed after a prolonged period of NREM sleep in normal mammals, it can be speculated that suppression of REM sleep by orexin-A administration may occur secondary to suppression of NREM sleep. If REM sleep suppression by orexin-A resulted solely from indirect effects of NREM sleep suppression, and orexin-A had no influence on transitions from NREM to REM sleep, the emergence of REM sleep episodes would likely depend simply on the amount of preceding NREM sleep. After orexin-A administration, $\mathrm{OX}_{2} \mathrm{R}^{-/-}$mice spent significantly longer in NREM sleep than did $O X_{1} R^{-1-}$ mice, whereas $O X_{1} R^{-/-}$and $O X_{2} R^{-I-}$ mice spent similar durations in REM sleep (Figs. 1, 2). Thus, in addition to the indirect effects, ICV-administered orexin-A is likely to suppress transitions from NREM sleep to REM sleep directly. In $\mathrm{OX}_{2} \mathrm{R}^{-1-}$ mice, furthermore, 1 and 3 nmol orexin-A administration suppressed NREM sleep to a similar degree, but orexin-A suppressed REM sleep more potently at $3 \mathrm{nmol}$ than $1 \mathrm{nmol}$ (Fig. $3 A-C)(n=6, p=$ 0.0252 for $C$ ). Consistently, latency to REM sleep was not correlated with latency to NREM sleep after administration of 1 or 3 nmol of orexin-A in $\mathrm{OX}_{2} R^{-1-}$ mice $(r=-0.0407, p=0.9001)$, but these parameters were highly correlated in $O X_{1} R^{-/-}$mice 
A TMN

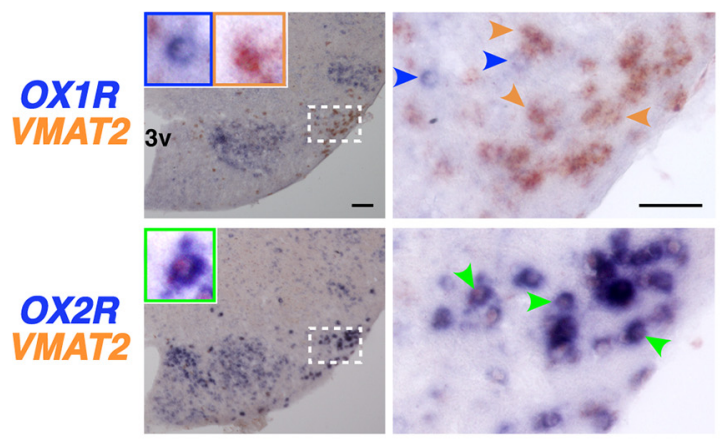

\section{LC}

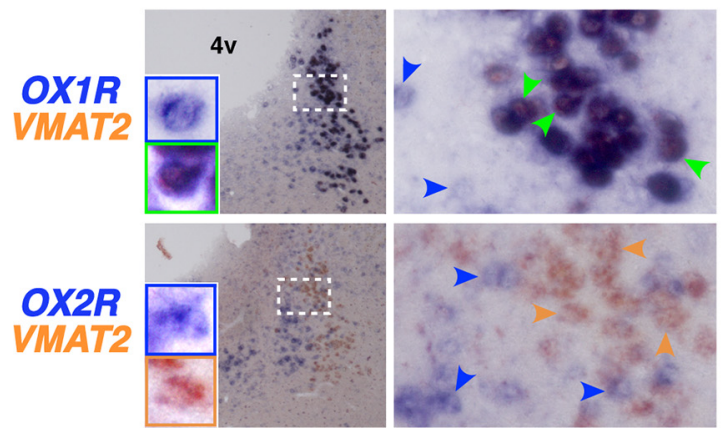

B DR

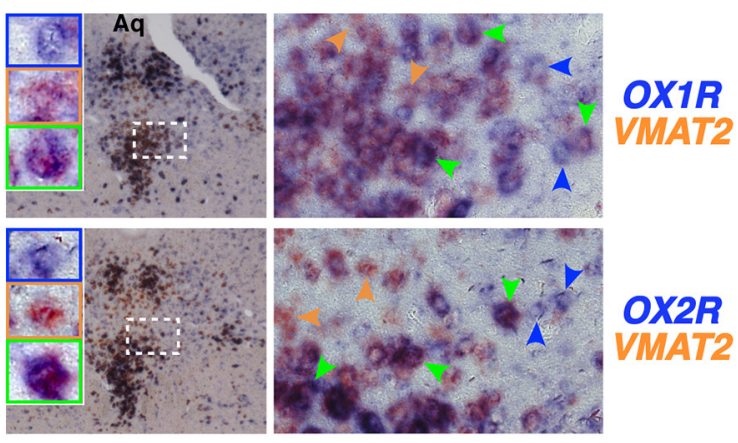

\section{LDT}

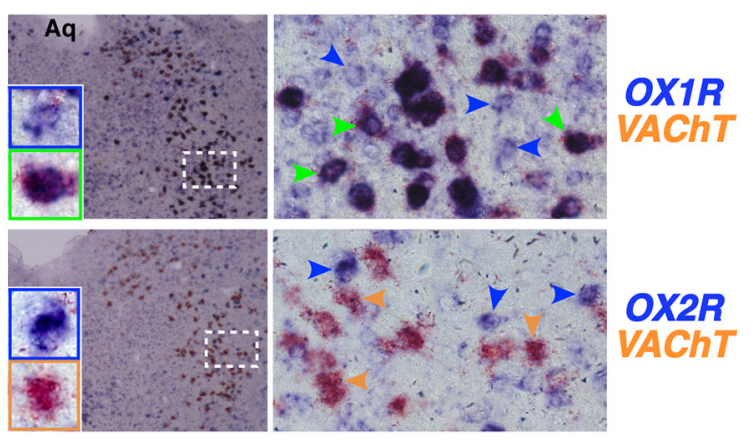

Figure 5. Differential distribution of $O X_{7} R$ and $O X_{2} R$ mRNA in monoaminergic and cholinergic neurons implicated in regulation of wakefulness. $\boldsymbol{A}-\boldsymbol{D}$, Coronal brain sections containing TMN ( $\left.\boldsymbol{A}\right)$, DR $(\boldsymbol{B}), \mathrm{LC}(\boldsymbol{C})$, and LDT $(\boldsymbol{D})$ from wild-type mice were hybridized in situ to an $O X_{7} R$ (top) or $O X_{2} R$ (bottom) antisense probe (blue stain) combined with either a monoaminergic marker VMAT2 [histaminergic $(\boldsymbol{A})$, serotonergic $(\boldsymbol{B})$, noradrenergic neurons $(\boldsymbol{C})$ ] or cholinergic marker VAChT $(\boldsymbol{D})$ antisense probe (orange stain). The locations and sizes of magnified images (right) are shown by white rectangles in the low-power images (left). Representative cells stained blue, orange, or both are indicated by blue, orange, and green arrowheads, respectively. Enlargements of some of these representative cells are shown in insets of the left panels. $3 \mathrm{v}$, Third ventricle; $4 \mathrm{v}$, fourth ventricle; Aq, aqueduct. Scale bars: (in $\boldsymbol{A}) \boldsymbol{A}-\boldsymbol{D}, 100$ and $50 \mu \mathrm{m}$ for low- and high-power images, respectively.

$(r=0.8332, p<0.0001)$ (Fig. 3D). These results suggest that the orexin-A-mediated inhibition of REM sleep through $\mathrm{OX}_{2} \mathrm{R}$ is largely dependent on inhibition of the preceding NREM sleep, but that the orexin-A-mediated REM sleep inhibition through $\mathrm{OX}_{1} \mathrm{R}$ may involve a mechanism independent of the effect on NREM sleep. These observations again indicate the existence of independent pathways that regulate NREM and REM sleep by orexin-A, and further implicate $\mathrm{OX}_{1} \mathrm{R}$ in the gating of NREM/ REM sleep transitions.

\section{Differential expression of orexin receptors in neurons with specific neurotransmitter identities in nuclei implicated in sleep/wake regulation}

To further understand the molecular basis underlying differential roles of orexin receptors in sleep/wakefulness, we next examined their mRNA expression in neurons implicated in sleep/wakefulness regulation. We first compared expression patterns of $O X_{1} R$ and $O X_{2} R$ mRNA in wild-type, $O X_{1} R^{-/-}$, and $O X_{2} R^{-/-}$mice by in situ hybridization. In wild-type mice, consistent with previous studies (Trivedi et al., 1998; Marcus et al., 2001), the tuberomammillary nucleus (TMN) abundantly expressed $\mathrm{OX}_{2} R$ (Fig. 4A), and the locus ceruleus (LC) predominantly expressed $O X_{1} R$ (Fig. $4 B$ ). In the laterodorsal tegmental nucleus (LDT) and pedunculopontine tegmental nucleus (PPT), many $O X_{1} R$-positive cells and fewer $\mathrm{OX}_{2} \mathrm{R}$-positive cells with a scattered distribution were observed (Fig. 4D) (data not shown). In the dorsal and median raphe nuclei (DR and $\mathrm{MnR}$ ), $O X_{1} R$ and $O X_{2} R$ mRNA showed intense labeling with similar spatial patterns (Fig. 4C) (data not shown). These distributions of $O X_{1} R$ and $O X_{2} R$ mRNA were essentially unchanged in mice lacking the other subtype of orexin receptor (Fig. 4A-D), suggesting that genetic deletion of one subtype does not affect the spatial expression pattern of the remaining subtype. Importantly, no significant signal of $O X_{1} R$ and $O X_{2} R$ was detected in $O X_{1} R^{-/-}$and $O X_{2} R^{-/-}$mice, respectively, confirming specificity of the riboprobes used in this study.

Monoaminergic (i.e., histaminergic, noradrenergic, and serotonergic) and cholinergic neurons in these nuclei have been considered critical for sleep/wakefulness regulation (Pace-Schott and Hobson, 2002; Sakurai, 2007). However, the expression patterns of orexin receptors in these neurochemically defined cells have remained uncertain. Thus, we next performed double in situ hybridization to elucidate histologically the subtype of orexin receptors expressed in these neurons, using vesicular monoamine transporter 2 (VMAT2) and vesicular acetylcholine transporter (VAChT) as molecular markers for monoaminergic and cholinergic neurons, respectively (Erickson et al., 1992; Roghani et al., 1994). In addition, we also examined coexpression of orexin receptor mRNA and a GABAergic marker glutamic acid decarboxylase 1 (Gad1) mRNA in these monoaminergic and cholinergic nuclei (Huang et al., 1990), in view of the possible importance of GABAergic interneurons in their functions.

In the TMN (Fig. 5A), we found many cells stained singly in orange (VMAT2) when sections were hybridized to $O X_{1} R$ and $V M A T 2$ probes (top). In contrast, when hybridized to $O X_{2} R$ and VMAT2 probes (Fig. 5A, bottom), we observed many cells doubly stained in blue $\left(\mathrm{OX}_{2} \mathrm{R}\right)$ and orange (VMAT2) but no cell singly stained in orange. These results suggested that VMAT2-positive histaminergic neurons did not express a detectable level of $O X_{1} R$ mRNA, while $\mathrm{OX}_{2} R$ mRNA was colocalized in all VMAT2positive neurons. Notably, we detected Gad1 mRNA in virtually 


\section{A TMN}

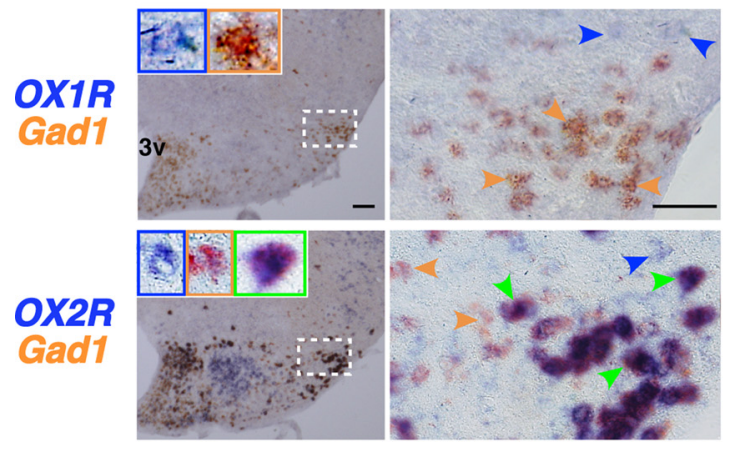

\section{LC}

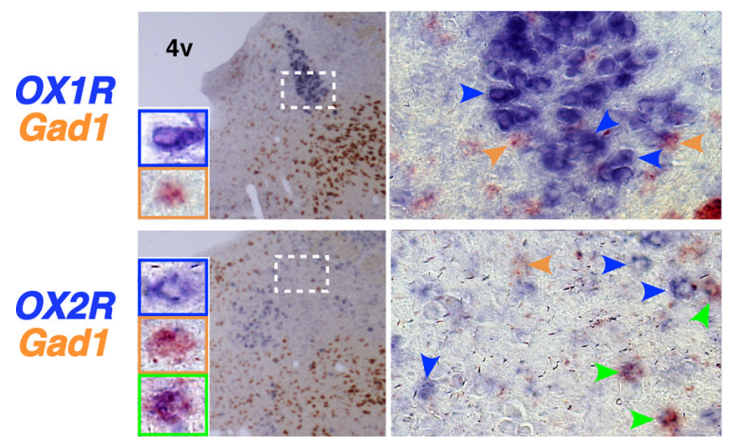

\section{B DR}

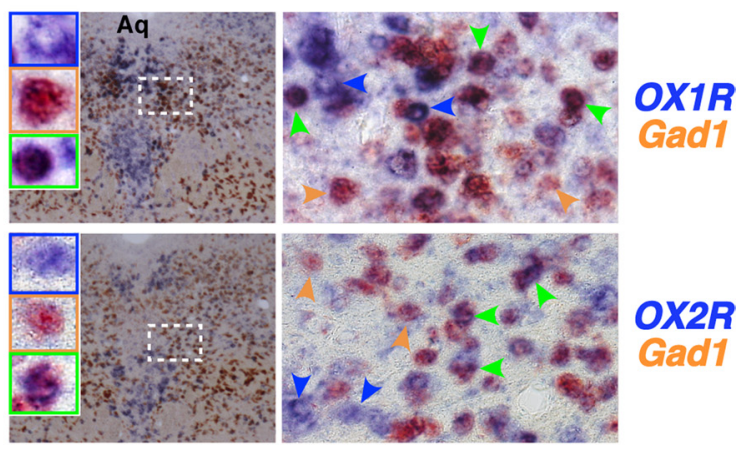

\section{LDT}

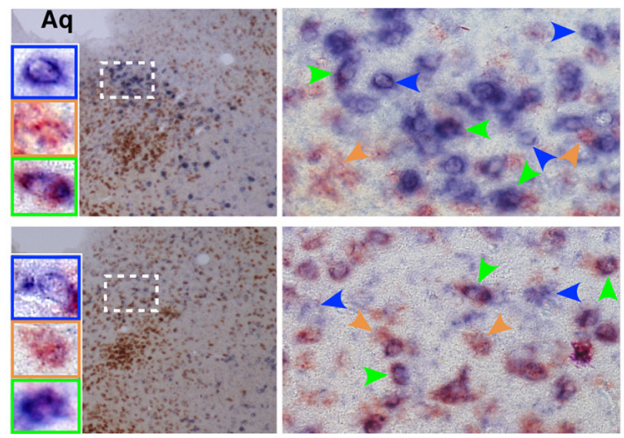

OX1R

Gad1

OX2R

Gad1

Figure 6. Differential distributions of $O X_{7} R$ and $O X_{2} R$ mRNA in GABAergic neurons in wake-promoting nuclei. $\boldsymbol{A}-\boldsymbol{D}$, Coronal brain sections containing TMN $(\boldsymbol{A})$, DR $(\boldsymbol{B})$, LC ( $\boldsymbol{C}$ ), and LDT ( $\left.\boldsymbol{D}\right)$ from wild-type mice were hybridized in situ to an $O X_{7} R$ (top) or $O X_{2} R$ (bottom) antisense probe (blue stain) combined with a GABAergic marker Gad 1 (orange stain). The locations and sizes of magnified images (right) are shown by white rectangles in the low-power images (left). Representative cells stained blue, orange, or both are indicated by blue, orange, green arrowheads, respectively. Enlargements of some of these representative cells are shown in insets of the left panels. $3 \mathrm{v}$, Third ventricle; $4 \mathrm{v}$, fourth ventricle; Aq, aqueduct. Scale bars: (in $\boldsymbol{A}$ ) $\boldsymbol{A}-\boldsymbol{D}, 100$ and $50 \mu \mathrm{m}$ for low- and high-power images, respectively.

all $\mathrm{OX}_{2} \mathrm{R}$-expressing TMN neurons, suggesting that histaminergic neurons are also GABAergic (Fig. $6 A$ ). In addition, we found a few VMAT2-negative/Gad1-negative cells expressing $O X_{1} R$ mRNA in the same area.

In the DR (Fig. 5B) and MnR (data not shown), we detected both $O X_{1} R$ and $O X_{2} R$ mRNA in $~ 90 \%$ of VMAT2-positive serotonergic neurons (DR: $87.4 \%$ and $89.5 \%$, MnR: $96.6 \%$ and $92.2 \%$ for $O X_{1} R$ and $O X_{2} R$, respectively), suggesting that the majority of serotonergic neurons in these areas express both $O X_{1} R$ and $\mathrm{OX}_{2} R$. Many VMAT2-negative nonserotonergic cells in the DR/ $\mathrm{MnR}$ also expressed $O X_{1} R$ or $O X_{2} R$ mRNA. At least some populations of these cells were likely to be GABAergic, since a population of Gad1-positive cells demonstrated detectable $O X_{1} R$ or $\mathrm{OX}_{2} \mathrm{R}$ mRNA (Fig. $6 \mathrm{~B}$ ). We could not conclude whether a single population of GABAergic neurons expressed both receptors or whether different populations expressed either $O X_{1} R$ or $\mathrm{OX}_{2} \mathrm{R}$.

In the LC (Fig. 5C), all VMAT2-positive noradrenergic neurons exhibited intense $O X_{1} R$ expression, whereas $O X_{2} R$ mRNA was exclusively detected in VMAT2-negative nonnoradrenergic neurons. Only some of these $\mathrm{OX}_{2} R$-expressing cells exhibited Gad1 expression, leaving the remaining cells neurochemically unidentified (Fig. 6C).

In the LDT (Fig. 5D) and PPT (data not shown), all VAChTpositive cholinergic neurons expressed $O X_{1} R$ but not $O X_{2} R$ mRNA, but many $O X_{1} R$-positive and/or $O X_{2} R$-positive noncholinergic neurons were intermingled with cholinergic neurons in the area. Gad1 mRNA staining further revealed that $O X_{1} R$ - or $\mathrm{OX}_{2} \mathrm{R}$-expressing cells included both GABAergic and non-
GABAergic cells (Fig. 6 D). A previous study showed that $\sim 50 \%$ of ChAT-immunoreactive neurons in the LDT/PPT also contained GABA (Jia et al., 2003), and our double in situ hybridization using VAChT and Gadl probes confirmed at least the existence of such cholinergic/GABAergic neurons (data not shown). Thus, in the LDT/PPT, these results suggest that: (1) $O X_{1} R$ mRNA is expressed in all cholinergic neurons and possibly in GABAergic and neurochemically unidentified neurons, and (2) $\mathrm{OX}_{2} R$ mRNA is expressed in GABAergic and neurochemically unidentified neurons but not in cholinergic neurons. Whether both $O X_{1} R$ and $O X_{2} R$ are expressed in the same populations of GABAergic or unidentified neurons remains unknown.

This differential expression of $O X_{1} R$ and $O X_{2} R$ is summarized in Figure 7.

\section{Discussion}

In the present study, we compared the contribution of $\mathrm{OX}_{1} \mathrm{R}$ and $\mathrm{OX}_{2} \mathrm{R}$ to the effects of ICV orexin-A administration on sleep and wakefulness using mice lacking either $O X_{1} R$ or $O X_{2} R$. We administered orexin- $\mathrm{A}$, the dual $\mathrm{OX}_{1} \mathrm{R} / \mathrm{OX}_{2} \mathrm{R}$ agonist, in all mice. Furthermore, we used knock-out mice to assure specific and complete deletion of orexin receptor genes. Hence our strategy eliminated confounding factors that could affect results from studies that use subtype-selective orexin agonists and/or antagonists, such as specificity, potency, efficacy, occupancy, and stability of the administered drugs. In addition, the current lack of availability of an $\mathrm{OX}_{1} \mathrm{R}$-selective agonist supports our strategy. It is possible that the lack of one receptor subtype might be compensated by enhanced expression of the other subtype. However, 
we found that genetic deletion of $O X_{1} R$ or $\mathrm{OX}_{2} \mathrm{R}$ did not result in an overt change in the distribution of the other subtype mRNA (Fig. 4). However, whether the intensity of expression of the other receptor is altered remains unknown.

In this study, we demonstrated that activation of $\mathrm{OX}_{2} \mathrm{R}$ promotes wakefulness and suppresses NREM sleep with substantially higher efficacy than that of $\mathrm{OX}_{1} \mathrm{R}$. In contrast, both $\mathrm{OX}_{1} \mathrm{R}$ and $\mathrm{OX}_{2} \mathrm{R}$ appear to be involved in the suppression of REM sleep by orexin-A administration to a similar degree. These findings are consistent with the conclusion derived from behavioral studies and baseline sleep/wakefulness recordings of $O X_{1} R^{-/-}$and $\mathrm{OX}_{2} R^{-/-}$mice: the normal regulation of wakefulness/NREM sleep transitions depends critically on $\mathrm{OX}_{2} \mathrm{R}$, but the profound dysregulation of REM sleep control unique to narcolepsy-cataplexy syndromes emerges from loss of signaling through both $\mathrm{OX}_{1} \mathrm{R}$ and $\mathrm{OX}_{2} \mathrm{R}$ (Willie et al., 2003; Sakurai, 2007). A previous pharmacological study using $\mathrm{OX}_{1} \mathrm{R}$ - and $\mathrm{OX}_{2} \mathrm{R}$-selective antagonists in rats also demonstrated a principal role of $\mathrm{OX}_{2} \mathrm{R}$ in suppression of NREM sleep (Dugovic et al., 2009). Furthermore, ICV administration of an $\mathrm{OX}_{2} \mathrm{R}$-selective agonist $\left[\mathrm{Ala}^{11}\right]$ orexin-B in rats was sufficient to promote wakefulness and suppress NREM and REM sleep (Akanmu and Honda, 2005).

Histaminergic neurons in the TMN are believed to play an important role in the wake-promoting effect of orexin, since the effects of ICV orexin-A administration are markedly attenuated by the histamine $\mathrm{H}_{1}$ receptor $\left(\mathrm{H}_{1} \mathrm{R}\right)$ antagonist pyrilamine and are absent in $H_{1} R^{-/-}$mice (Huang et al., 2001; Yamanaka et al., 2002). The TMN abundantly expresses $\mathrm{OX}_{2} \mathrm{R}$, supporting a critical contribution of TMN histaminergic neurons (Marcus et al., 2001; Yamanaka et al., 2002). Here, and in agreement with the previous studies, we showed marked attenuation of orexin-A-induced wakefulness in $\mathrm{OX}_{2} R^{-/-}$mice. Additionally, we demonstrated expression of $\mathrm{OX}_{2} \mathrm{R}$ mRNA in almost all TMN histaminergic neurons, which is consistent with a previous immunohistochemical study (Yamanaka et al., 2002). Interestingly, our results suggested coexpression of histaminergic and GABAergic molecular markers with $\mathrm{OX}_{2} \mathrm{R}$ in the TMN, consistent with previous studies showing that TMN histaminergic neurons contain GABA (Ericson et al., 1991; Airaksinen et al., 1992). Despite dense histaminergic innervation to the ventrolateral preoptic area (VLPO) from TMN, histamine reportedly has no effect on sleep-promoting neurons of this area, which is in notable contrast to the inhibitory effects of noradrenaline, serotonin, and acetylcholine (Gallopin et al., 2000; Chou et al., 2002). In addition, histidine decarboxylase ${ }^{-1-}$ and $H_{1} R^{-/-}$mice show mild or subtle phenotypes concerning sleep/wakefulness regulation under baseline conditions, clearly contrasting with $\mathrm{OX}_{2} \mathrm{R}^{-/-}$ mice, which show marked abnormalities in sleep and wakefulness (Parmentier et al., 2002; Willie et al., 2003; Huang et al., 2006; Hondo et al., 2010). Furthermore, $\mathrm{OX}_{1} \mathrm{R}^{-1-} ; \mathrm{H}_{1} \mathrm{R}^{-/-}$mice also show no detectable abnormality in sleep/wakefulness states
(Hondo et al., 2010). Thus, GABAergic transmission by TMN histaminergic neurons, driven by the OX2R (Willie et al., 2003), may play a critical role, including suppression of sleeppromoting neurons in the VLPO.

However, orexin-A administration in $\mathrm{OX}_{2} R^{-/-}$mice still caused an increase in wakefulness. Thus, $\mathrm{OX}_{1} \mathrm{R}$-expressing neurons may also play a role in the effects of orexin-A. Consistent with this thesis, fragmentation of wakefulness in $\mathrm{OX}_{2} R^{-/-}$mice is milder than that in $\mathrm{OX}_{1} R^{-/-} ; \mathrm{OX}_{2} R^{-/-}$mice (Sakurai, 2007). In addition, ICV administration of an $\mathrm{OX}_{2} \mathrm{R}$-selective agonist $\left[\right.$ Ala ${ }^{11}$ ] orexin-B seemed less effective when compared with orexin-A (Akanmu and Honda, 2005). However, ICV administration of orexin-A in $\mathrm{OX}_{2} \mathrm{R}$-deficient dogs has been reported to have no effect on time spent in wakefulness (Fujiki et al., 2003). This discrepancy between the studies with $\mathrm{OX}_{2} R$-defficient mice and dogs may be explained by differences in doses, time windows of analyses, numbers of animals examined, and species (Willie et al., 2003).

LC noradrenergic neurons, which abundantly express $\mathrm{OX}_{1} \mathrm{R}$, are one of the candidate systems to mediate the arousal effect mediated by $\mathrm{OX}_{1} \mathrm{R}$. Indeed, microinjection of orexin-A into the LC increases wakefulness (Bourgin et al., 2000). Other regions that could mediate $\mathrm{OX}_{1} \mathrm{R}$-induced arousal effects include cholinergic neurons in the LDT/PPT and serotonergic neurons in the raphe nuclei, both of which are thought to be critically involved in the regulation of sleep/wakefulness states (Pace-Schott and Hobson, 2002; Sakurai, 2007). Redundant expression of both $O X_{1} R$ and $O X_{2} R$ mRNA was reported in raphe nuclei (Marcus et al., 2001). We showed that most serotonergic neurons in the DR and MnR are positive for $O X_{1} R$ and/or $O X_{2} R$ mRNA, which is in accordance with a previous single-cell PCR study (Brown et al., 
2002). In addition to the direct excitatory effects, orexins act indirectly to activate local inhibitory GABAergic input to serotonergic neurons (Liu et al., 2002). This is consistent with our present finding of expression of orexin receptors in GABAergic neurons of the DR/MnR.

In contrast to the regulation of wakefulness/NREM sleep transitions, orexin-A suppressed REM sleep similarly in $O X_{1} R^{-/-}$ and $\mathrm{OX}_{2} R^{-/-}$mice. Considering that $\mathrm{OX}_{2} R^{-/-}$mice spent longer in NREM sleep than did $O X_{1} R^{-/-}$mice after orexin-A administration, activation of $\mathrm{OX}_{1} \mathrm{R}$ may more potently suppress REM sleep than does $\mathrm{OX}_{2} \mathrm{R}$. Our observations further suggest that orexin-A directly suppresses transitions from NREM sleep to REM sleep, and that activation of $\mathrm{OX}_{1} \mathrm{R}$ is sufficient for this effect. $\mathrm{OX}_{2} \mathrm{R}$ activation may suppress REM sleep directly at the transition from NREM sleep and/or indirectly at the transition from wakefulness to NREM sleep. Paradoxically, in vivo single-unit recordings revealed that orexin neurons discharge during active waking, have decreased firing rates during quiet waking, and virtually cease firing during both REM and NREM sleep (Lee et al., 2005; Mileykovskiy et al., 2005; Takahashi et al., 2008). It is possible that extremely low activity of orexin neurons or residual orexin neuropeptides in the extracellular fluid during NREM sleep after wakefulness may prevent the induction of REM sleep.

Previous findings also suggest gating of NREM/REM sleep transitions by orexin-A. First, local administration of orexin-A into the LC of rats, which abundantly expresses $\mathrm{OX}_{1} \mathrm{R}$, suppressed REM sleep without significant alteration in NREM sleep (Bourgin et al., 2000). Second, systemic administration of a selective $\mathrm{OX}_{1} \mathrm{R}$ antagonist SB-334867 reversed REM sleep suppression caused by ICV orexin-A administration at a dose which produced no significant change in NREM sleep (Smith et al., 2003). In addition, deficiency in this type of REM sleep regulation may underlie the unproportionally large increase in REM sleep time when compared with the increase in NREM sleep in narcoleptic orexin ${ }^{-/-}$and $\mathrm{OX}_{1} \mathrm{R}^{-/-} ; \mathrm{OX}_{2} \mathrm{R}^{-/-}$mice (Chemelli et al., 1999; Sakurai, 2007). These observations suggest that orexin-Amediated suppression of REM sleep might primarily be mediated by noradrenergic neurons in the LC, which send collateral projections to cholinergic neurons in the LDT/PPT.

Differential expression of orexin receptors in cholinergic and GABAergic neurons of the LDT/PPT is also intriguing. Exclusive expression of $O X_{1} R$ in cholinergic neurons is also supported by a previous study demonstrating that the excitatory effects of orexin-A on PPT cholinergic neurons were suppressed by a selective $\mathrm{OX}_{1} \mathrm{R}$ antagonist SB-334867 (Kim et al., 2009). Cholinergic neurons in these areas include those that are active during wakefulness and REM sleep (W/REM-on neurons) and those that are specifically active during REM sleep (REM-on neurons) (PaceSchott and Hobson, 2002; Sakurai, 2007). The latter population is likely to play a critical role in REM sleep-related physiological phenomena, including muscle atonia. Nevertheless, orexin-A excites both cholinergic and noncholinergic neurons of the LDT in slice preparations (Burlet et al., 2002). Furthermore, orexin-A microinjection in the cat LDT increases wakefulness and reduces REM sleep (Xi et al., 2001). A recent study suggested that GABAergic neurons in the PPT mediate suppression of REM sleep and muscle atonia following local injection of orexin-A into this area (Takakusaki et al., 2005).Together, these results indicate that in the LDT/PPT, orexin may activate W/REM-on cholinergic neurons through $\mathrm{OX}_{1} \mathrm{R}$ to facilitate wakefulness. Simultaneously, orexin might activate GABAergic interneurons to inhibit REM-on cholinergic neurons in these nuclei. Additionally, orexinergic activation of wake-active noradrenergic and serotonergic neurons in the LC and raphe nuclei is likely to counteract activation of REM-on cholinergic neurons in the LDT/PPT during wakefulness (Pace-Schott and Hobson, 2002; Sakurai, 2007). This is consistent with the fact that tricyclic antidepressants and serotonin-specific reuptake inhibitors are effective for treating cataplexy in narcoleptic patients.

In conclusion, our findings highlight the complex redundant and/or compensatory pathways involving $\mathrm{OX}_{1} \mathrm{R}$ and $\mathrm{OX}_{2} \mathrm{R}$ mediating the effects of orexin-A administration on sleep/wakefulness regulation (Fig. 7). Thus, dual agonists for both $\mathrm{OX}_{1} \mathrm{R}$ and $\mathrm{OX}_{2} \mathrm{R}$ might have greater potential than subtype-selective agonists as novel treatments for narcolepsy and other states of hypersomnolence.

\section{References}

Airaksinen MS, Alanen S, Szabat E, Visser TJ, Panula P (1992) Multiple neurotransmitters in the tuberomammillary nucleus: comparison of rat, mouse, and guinea pig. J Comp Neurol 323:103-116.

Akanmu MA, Honda K (2005) Selective stimulation of orexin receptor type 2 promotes wakefulness in freely behaving rats. Brain Res 1048:138-145.

Bourgin P, Huitrón-Résendiz S, Spier AD, Fabre V, Morte B, Criado JR, Sutcliffe JG, Henriksen SJ, de Lecea L (2000) Hypocretin-1 modulates rapid eye movement sleep through activation of locus coeruleus neurons. J Neurosci 20:7760-7765.

Brisbare-Roch C, Dingemanse J, Koberstein R, Hoever P, Aissaoui H, Flores S, Mueller C, Nayler O, van Gerven J, de Haas SL, Hess P, Qiu C, Buchmann S, Scherz M, Weller T, Fischli W, Clozel M, Jenck F (2007) Promotion of sleep by targeting the orexin system in rats, dogs and humans. Nat Med 13:150-155.

Brown RE, Sergeeva O, Eriksson KS, Haas HL (2002) Convergent excitation of dorsal raphia serotonin neurons by multiple arousal systems (orexin/ hypocretin, histamine and noradrenaline). J Neurosci 22:8850-8859.

Burlet S, Tyler CJ, Leonard CS (2002) Direct and indirect excitation of laterodorsal tegmental neurons by Hypocretin/Orexin peptides: implications for wakefulness and narcolepsy. J Neurosci 22:2862-2872.

Chemelli RM, Willie JT, Sinton CM, Elmquist JK, Scammell T, Lee C, Richardson JA, Williams SC, Xiong Y, Kisanuki Y, Fitch TE, Nakazato M, Hammer RE, Saper CB, Yanagisawa M (1999) Narcolepsy in orexin knockout mice: molecular genetics of sleep regulation. Cell 98:437-451.

Chou TC, Bjorkum AA, Gaus SE, Lu J, Scammell TE, Saper CB (2002) Afferents to the ventrolateral preoptic nucleus. J Neurosci 22:977-990.

Date Y, Ueta Y, Yamashita H, Yamaguchi H, Matsukura S, Kangawa K, Sakurai T, Yanagisawa M, Nakazato M (1999) Orexins, orexigenic hypothalamic peptides, interact with autonomic, neuroendocrine and neuroregulatory systems. Proc Natl Acad Sci U S A 96:748-753.

de Lecea L, Kilduff TS, Peyron C, Gao X, Foye PE, Danielson PE, Fukuhara C, Battenberg EL, Gautvik VT, Bartlett FS 2nd, Frankel WN, van den Pol AN, Bloom FE, Gautvik KM, Sutcliffe JG (1998) The hypocretins: hypothalamus-specific peptides with neuroexcitatory activity. Proc Natl Acad Sci U S A 95:322-327.

Dugovic C, Shelton JE, Aluisio LE, Fraser IC, Jiang X, Sutton SW, Bonaventure P, Yun S, Li X, Lord B, Dvorak CA, Carruthers NI, Lovenberg TW (2009) Blockade of orexin-1 receptors attenuates orexin-2 receptor antagonism-induced sleep promotion in the rat. J Pharmacol Exp Ther 330:142-151.

Erickson JD, Eiden LE, Hoffman BJ (1992) Expression cloning of a reserpine-sensitive vesicular monoamine transporter. Proc Natl Acad Sci U S A 89:10993-10997.

Ericson H, Köhler C, Blomqvist A (1991) GABA-like immunoreactivity in the tuberomammillary nucleus: an electron microscopic study in the rat. J Comp Neurol 305:462-469.

Fujiki N, Yoshida Y, Ripley B, Mignot E, Nishino S (2003) Effects of IV and ICV hypocretin-1 (orexin A) in hypocretin receptor-2 gene mutated narcoleptic dogs and IV hypocretin-1 replacement therapy in a hypocretinligand-deficient narcoleptic dog. Sleep 26:953-959.

Gallopin T, Fort P, Eggermann E, Cauli B, Luppi PH, Rossier J, Audinat E, Mühlethaler M, Serafin M (2000) Identification of sleep-promoting neurons in vitro. Nature 404:992-995.

Hagan JJ, Leslie RA, Patel S, Evans ML, Wattam TA, Holmes S, Benham CD, Taylor SG, Routledge C, Hemmati P, Munton RP, Ashmeade TE, Shah 
AS, Hatcher JP, Hatcher PD, Jones DN, Smith MI, Piper DC, Hunter AJ, Porter RA, Upton N (1999) Orexin A activates locus coeruleus cell firing and increases arousal in the rat. Proc Natl Acad Sci USA 96:10911-10916.

Hondo M, Nagai K, Ohno K, Kisanuki Y, Willie JT, Watanabe T, Yanagisawa M, Sakurai T (2010) Histamine-1 receptor is not required as a downstream effector of orexin-2 receptor in maintenance of basal sleep/wake states. Acta Physiol (Oxf) 198:287-294.

Huang WM, Reed-Fourquet L, Wu E, Wu JY (1990) Molecular cloning and amino acid sequence of brain L-glutamate decarboxylase. Proc Natl Acad Sci U S A 87:8491-8495.

Huang ZL, Qu WM, Li WD, Mochizuki T, Eguchi N, Watanabe T, Urade Y, Hayaishi O (2001) Arousal effect of orexin A depends on activation of the histaminergic system. Proc Natl Acad Sci U S A 98:9965-9970.

Huang ZL, Mochizuki T, Qu WM, Hong ZY, Watanabe T, Urade Y, Hayaishi O (2006) Altered sleep-wake characteristics and lack of arousal response to $\mathrm{H} 3$ receptor antagonist in histamine $\mathrm{H} 1$ receptor knockout mice. Proc Natl Acad Sci U S A 103:4687-4692.

Jia HG, Yamuy J, Sampogna S, Morales FR, Chase MH (2003) Colocalization of gamma-aminobutyric acid and acetylcholine in neurons in the laterodorsal and pedunculopontine tegmental nuclei in the cat: a light and electron microscopic study. Brain Res 992:205-219.

Kim J, Nakajima K, Oomura Y, Wayner MJ, Sasaki K (2009) Electrophysiological effects of orexins/hypocretins on pedunculopontine tegmental neurons in rats: an in vitro study. Peptides 30:191-209.

Lee MG, Hassani OK, Jones BE (2005) Discharge of identified orexin/hypocretin neurons across the sleep-waking cycle. J Neurosci 25:6716-6720.

Lin L, Faraco J, Li R, Kadotani H, Rogers W, Lin X, Qiu X, de Jong PJ, Nishino S, Mignot E (1999) The sleep disorder canine narcolepsy is caused by a mutation in the hypocretin (orexin) receptor 2 gene. Cell 98:365-376.

Liu RJ, van den Pol AN, Aghajanian GK (2002) Hypocretins (orexins) regulate serotonin neurons in the dorsal raphe nucleus by excitatory direct and inhibitory indirect actions. J Neurosci 22:9453-9464.

Lubkin M, Stricker-Krongrad A (1998) Independent feeding and metabolic actions of orexins in mice. Biochem Biophys Res Commun 253:241-245.

Marcus JN, Aschkenasi CJ, Lee CE, Chemelli RM, Saper CB, Yanagisawa M, Elmquist JK (2001) Differential expression of orexin receptors 1 and 2 in the rat brain. J Comp Neurol 435:6-25.

Mieda M, Willie JT, Hara J, Sinton CM, Sakurai T, Yanagisawa M (2004) Orexin peptides prevent cataplexy and improve wakefulness in an orexin neuron-ablated model of narcolepsy in mice. Proc Natl Acad Sci U S A 101:4649-4654.

Mieda M, Williams SC, Richardson JA, Tanaka K, Yanagisawa M (2006) The dorsomedial hypothalamic nucleus as a putative food-entrainable circadian pacemaker. Proc Natl Acad Sci U S A 103:12150-12155.

Mileykovskiy BY, Kiyashchenko LI, Siegel JM (2005) Behavioral correlates of activity in identified hypocretin/orexin neurons. Neuron 46:787-798.

Nambu T, Sakurai T, Mizukami K, Hosoya Y, Yanagisawa M, Goto K (1999) Distribution of orexin neurons in the adult rat brain. Brain Res 827:243-260.

Nishino S, Ripley B, Overeem S, Lammers GJ, Mignot E (2000) Hypocretin (orexin) deficiency in human narcolepsy. Lancet 355:39-40.

Pace-Schott EF, Hobson JA (2002) The neurobiology of sleep: genetics, cellular physiology and subcortical networks. Nat Rev Neurosci 3:591-605.

Parmentier R, Ohtsu H, Djebbara-Hannas Z, Valatx JL, Watanabe T, Lin JS (2002) Anatomical, physiological, and pharmacological characteristics of histidine decarboxylase knock-out mice: evidence for the role of brain histamine in behavioral and sleep-wake control. J Neurosci 22:76957711.

Peyron C, Tighe DK, van den Pol AN, de Lecea L, Heller HC, Sutcliffe JG, Kilduff TS (1998) Neurons containing hypocretin (orexin) project to multiple neuronal systems. J Neurosci 18:9996-10015.

Peyron C, Faraco J, Rogers W, Ripley B, Overeem S, Charnay Y, Nevsimalova S, Aldrich M, Reynolds D, Albin R, Li R, Hungs M, Pedrazzoli M, Padigaru M, Kucherlapati M, Fan J, Maki R, Lammers GJ, Bouras C, Kucherlapati R, Nishino S, Mignot E (2000) A mutation in a case of early onset narcolepsy and a generalized absence of hypocretin peptides in human narcoleptic brains. Nat Med 6:991-997.

Piper DC, Upton N, Smith MI, Hunter AJ (2000) The novel brain neuropeptide, orexin-A, modulates the sleep-wake cycle of rats. Eur J Neurosci 12:726-730.

Roghani A, Feldman J, Kohan SA, Shirzadi A, Gundersen CB, Brecha N, Edwards RH (1994) Molecular cloning of a putative vesicular transporter for acetylcholine. Proc Natl Acad Sci U S A 91:10620-10624.

Sakurai T (2007) The neural circuit of orexin (hypocretin): maintaining sleep and wakefulness. Nat Rev Neurosci 8:171-181.

Sakurai T, Amemiya A, Ishii M, Matsuzaki I, Chemelli RM, Tanaka H, Williams SC, Richardson JA, Kozlowski GP, Wilson S, Arch JR, Buckingham RE, Haynes AC, Carr SA, Annan RS, McNulty DE, Liu WS, Terrett JA, Elshourbagy NA, Bergsma DJ, Yanagisawa M (1998) Orexins and orexin receptors: a family of hypothalamic neuropeptides and G proteincoupled receptors that regulate feeding behavior. Cell 92:573-585.

Smith MI, Piper DC, Duxon MS, Upton N (2003) Evidence implicating a role for orexin-1 receptor modulation of paradoxical sleep in the rat. Neurosci Lett 341:256-258.

Stricker-Krongrad A, Richy S, Beck B (2002) Orexins/hypocretins in the $\mathrm{ob} / \mathrm{ob}$ mouse: hypothalamic gene expression, peptide content and metabolic effects. Regul Pept 104:11-20.

Takahashi K, Lin JS, Sakai K (2008) Neuronal activity of orexin and nonorexin waking-active neurons during wake-sleep states in the mouse. Neuroscience 153:860-870.

Takakusaki K, Takahashi K, Saitoh K, Harada H, Okumura T, Kayama Y, Koyama Y (2005) Orexinergic projections to the cat midbrain mediate alternation of emotional behavioural states from locomotion to cataplexy. J Physiol 568:1003-1020.

Thannickal TC, Moore RY, Nienhuis R, Ramanathan L, Gulyani S, Aldrich M, Cornford M, Siegel JM (2000) Reduced number of hypocretin neurons in human narcolepsy. Neuron 27:469-474.

Trivedi P, Yu H, MacNeil DJ, Van der Ploeg LH, Guan XM (1998) Distribution of orexin receptor mRNA in the rat brain. FEBS Lett 438:71-75.

van den Pol AN (1999) Hypothalamic hypocretin (orexin): robust innervation of the spinal cord. J Neurosci 19:3171-3182.

Willie JT, Chemelli RM, Sinton CM, Tokita S, Williams SC, Kisanuki YY, Marcus JN, Lee C, Elmquist JK, Kohlmeier KA, Leonard CS, Richardson JA, Hammer RE, Yanagisawa M (2003) Distinct narcolepsy syndromes in Orexin receptor-2 and Orexin null mice: molecular genetic dissection of non-REM and REM sleep regulatory processes. Neuron 38:715-730.

Xi MC, Morales FR, Chase MH (2001) Effects on sleep and wakefulness of the injection of hypocretin-1 (orexin-A) into the laterodorsal tegmental nucleus of the cat. Brain Res 901:259-264.

Yamanaka A, Tsujino N, Funahashi H, Honda K, Guan JL, Wang QP, Tominaga M, Goto K, Shioda S, Sakurai T (2002) Orexins activate histaminergic neurons via the orexin 2 receptor. Biochem Biophys Res Commun 290:1237-1245. 